\title{
Integrated Macro-Micro-Symbolic Approach in Teaching Secondary Chemistry
}

\author{
Joje Mar P. Sanchez* \\ College of Teacher Education, Cebu Normal University, Osmeña Boulevard, Cebu City 6000
}

\begin{abstract}
The purpose of this paper is to investigate the effectiveness of the Integrated Macro-Micro-Symbolic Approach (IMMSA) in teaching Chemistry to 10th graders of a secondary school in Cebu City, Philippines. A pre-post quasi-experimental design with control group was utilized to two groups of students, of which one was exposed to IMMSA and the other to conventional lecture method (CLM). Topics included in the experimentation proper were the five postulates of the Kinetic Molecular Theory of gases. Data gathered from the pre- and post-test tools were analyzed using t-tests, with a level of significance, $\alpha=0.01$. Study findings revealed that both groups had Below Average performance levels in the pre- and post-test, where the lack of time and spiral progression were seen as reasons for the performances. The study also found that both groups had significantly increased their performances from the pre- to the post-tests, implying the essence of both lectures and integrated use of modes. Ultimately, the study revealed that IMMSA is more effective than CLM as seen in the students' enhanced performance, signifying the effective nature of the integration of macroscopic, microscopic and symbolic modes in teaching Chemistry concepts. With this, the Three-tiered model of learning and Chemistry triangle are still valued in the 21 st century learning environment.
\end{abstract}

Keywords: chemistry education; integrated macro-micro-symbolic approach; conventional lecture method

\section{INTRODUCTION}

Chemistry education contributes to scientific, technological and environmental literacy (Department of Education, 2013). According to the Royal Society of Chemistry (2011), such education has two distinct roles in schools. Firstly, Chemistry education prepares students to become scientifically literate citizens by equipping them with skills and understanding that are relevant and meaningful in their daily lives. Secondly, it provides knowledge and skills needed in the tertiary level of education. Moreover, it serves as the foundation of innovation and problem-solving initiatives for sustainable development in every country (Risch, 2010).

Despite the aforementioned roles played by Chemistry education, many consider the course as challenging and difficult (Childs and Sheehan, 2009; Sirhan, 2007; Woldeamanuel, Atagana and Engida, 2014). Johnstone (1982) argued that one of the sources of such difficulty is the method in which Chemistry is taught. For instance, a Chemistry teacher is having a lesson on chemical reactions. Usually, the teacher begins the lesson by defining what chemical reactions are, and afterwards, extends it by describing evidences of chemical reactions, though without the experimental experience (Nelson, 2002). Even without such experience, he then proceeds to giving examples in symbols and formulas, giving the impression that the lesson is too abstract, and uses unfamiliar language (Eilks and Hofstein, 2015). Moreover, the lesson drives towards balancing chemical equations, often without 
tackling the chemical reactions at submicroscopic level, resulting in misconceptions in the particulate nature of the phenomena (Harrison and Treagust, 2002). This scenario highlighted the need for an approach, a method, or a technique, which could incorporate the various levels of chemical representations in order to understand a particular phenomenon, which could solve the dilemma of Chemistry teachers in teaching abstract and difficult topics to the Filipino students.

Thus, the study addresses the problem arising from the interplay of the different levels by using an approach of teaching incorporating the macroscopic, microscopic and symbolic modes of representation, which are needed in effectively imparting chemical literacy and relevance to daily life. It is in the Integrated Macro-Micro-Symbolic approach (IMMSA) that students can use their senses in explaining a chemical phenomenon, support qualitative descriptions of the phenomenon at the atomic structural scale, represent it as law equations, and solve problems related to it.

Theoretical Background. Two related studies anchored the use of IMMSA in teaching Chemistry. The first one is Jerome Bruner's Three-Tiered Model of Learning which describes the learning modes or cognitive representations that when incorporated together create a variety of learning experiences wherein teachers and students discover ideas, solve problems, and reflect on meanings (Bruner, 1966; Ellis, 2001). The model's three-tier process characterizes the three stages of development, namely enactive, iconic and symbolic - a progression from concrete experiences to abstract representations (Bruner, 1966; Kincheloe and Horn, 2007). The other theory is Alex Johnstone's Chemistry Triangle. This theoretical framework views Chemistry in three levels of representation - macroscopic, submicroscopic and symbolic levels - which are represented as vertices of the triangle (Johnstone, 1982; Gilbert and Treagust, 2009; Cardellini, 2012). These two theories are essential in the development of IMMSA.

Literature Review. Since new learning partnerships emerge between and among students and teachers, various pedagogical approaches and methods were formulated in order to achieve the 21 st century skills needed by the students, especially in educational paradigm shifts such as the $\mathrm{K}$ to 12 basic education reform and the ASEAN integration. Among these pedagogies is the use of multiple representations in teaching. These representations are an advantage in teaching and learning scientific concept, as these support learning, constraint interpretation, and promote understanding (Ainsworth, 2007). In particular, three multiple representations are used

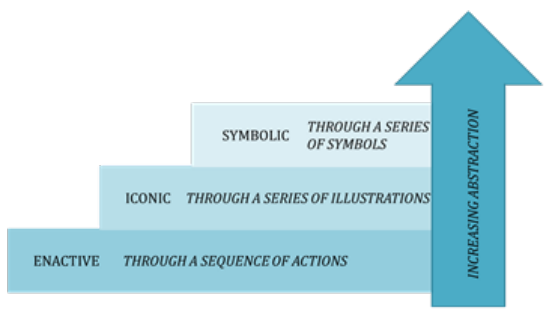

Figure 1. Three-tiered Model of Learning (Bruner, 1966).



Figure 2. Chemistry Triangle (Johnstone, 1982).

in Chemistry education. These representations, namely, macroscopic, microscopic and symbolic modes, constitute a key model in Chemistry (Gilbert and Treagust, 2009). This model reduces memory overload, and clarifies confusion of descriptive language (Bradley, 2014). Moreover, the significance of the model lies in the use of different modes in each level of representation. These modes which are vital in learning acquisitions include practical work, gestures, structural and virtual representations, photographs, diagrams, graphs, and chemical and mathematical equations (Gilbert, 2008; Schoenfeld, 2013).

The use of multiple representations in teaching and learning chemical concepts is an important application of the Chemistry Triangle. Jaber and Boujaode (2012) employed a macro-microsymbolic teaching on chemical reactions. Their study found that the intervention has improved the conceptual understanding of students, and has enhanced the relational understanding in chemical reactions. Wood (2013) examined the instructional use of symbolic, microscopic and macroscopic modes in the conceptual understanding of students. It was found that when macroscopic observations and particulate models are employed, there is a better conceptual understanding. Brandiet (2014) investigated how students explained redox reactions, and found that students seemed to have better understanding in the macroscopic-symbolic conditions than the macroscopic-particulate and symbolic-particulate relationships. Li and Arshad (2014) focused on the ability of their respondents to link one mode to another. They found that full integration of the three modes is rarely exhibited. Collating these studies, there is a need to examine the effectiveness of IMMSA in teaching other areas 
of Chemistry, particularly in the Kinetic Molecular Theory (KMT) of gases - a theory whose topics can be observed in every dealings, yet students have difficulty in relating these observable phenomena to the microscopic level, like behavior of molecules, and symbolic level, like problem-solving.

Statement of the Problem. The study determined the effectiveness of IMMSA in teaching Kinetic Molecular Theory of gases to $10^{\text {th }}$-grade students in a secondary school in Cebu City, Philippines. Specifically, it determined the pre- and post-test performances of those exposed to IMMSA and those exposed to conventional lecture method (CLM), determined whether there was a significant improvement in the performance of the students after the implementation of IMMSA and CLM, and determined whether there was a significant difference between the mean gains of the two groups of students.

\section{METHODOLOGY}

Research Design, Environment and Respondents. The study utilized the pre- and post-test quasiexperimental research design with control group in order to determine the effectiveness of IMMSA in teaching Chemistry. Two groups of 15 randomly selected 10th grade students from a secondary school in Cebu City, Philippines participated in the study. These participants were selected through fishbowl method randomization, and were exposed to a Chemistry course in their 9th grade.

Research Procedure and Data Analysis. Before experimentation occurred, the researcherconstructed assessment tool was validated by four expert Science professors from two well-respected state universities in Cebu City. To ensure reliability of the test, the tool was pilot-tested to the 10th grade students of the secondary department of one of the aforementioned universities. The 30-item tool consists of five parts, each corresponding to the postulates of the KMT of gases. Each part has a situation to analyze, and each part is divided into three tasks, which correspond to the three modes of representation. The first and second tasks consider the macroscopic and microscopic aspects, have two items each, and are scored 3 points each (1 point for $\mathrm{MC}$ item and 2 points for CR item). The third task deals with the symbolic aspect, has two items, and is scored 2 points (1 point each item). (Refer to Appendix A for the sample section of the research tool.)

Afterwards, research permission was sought from the executive director of the secondary school, as well as informed consent from the participants. Once permission was granted, the validated pre-test tool was administered to the two participating groups. After pre-testing, the two groups of Grade 10 students underwent the experimentation phase. The first group was exposed to CLM, while the other was exposed to IMMSA. After a month of experimentation, the two groups were given the post-test.

To analyze the data obtained from the assessment tool, t-test for single and small samples was employed. To determine whether there is a significant difference between the pre- and post-test performances, t-test for correlated samples was used. Lastly, in order to know the difference between the mean gains of the two groups, t-test for two independent samples was utilized. All tests were used at a level of significance, $\alpha=0.01$.

Research Pedagogies. The study utilized conventional lecture method (CLM) for one group of students, and the integrated macro-micro-symbolic approach (IMMSA) for other group. CLM infused teacherdirected laboratory and lecture formats. Lectures constituted classroom discussion, formulas giving and problem solving.

IMMSA integrated the three modes of chemical representations. The approach starts with a motivation and the presentation of the topic. Afterwards, laboratory activities (macroscopic

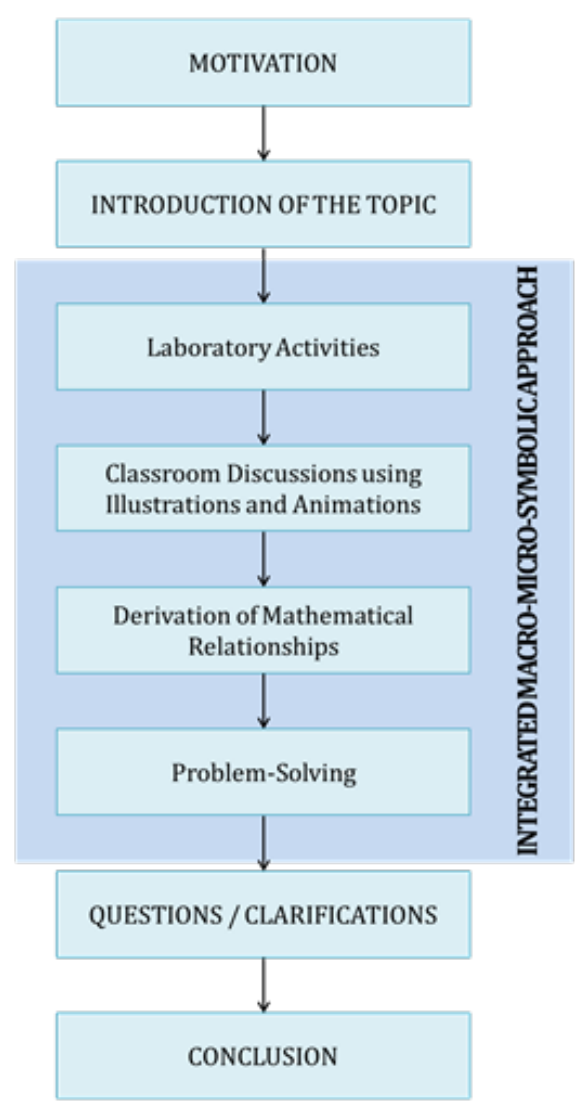

Figure 2. Flow of IMMSA. 
mode) are employed to the students. The experiments macroscopically describe five properties of gases: (a) diffusion, which correspond to the first postulate of KMT of gases, (b) pressure, volume and compressibility/expansibility, which corresponds to second, third and fourth postulates, and (c) temperature, which corresponds to the fifth postulate. Students observe these properties as they engage in different experiments. Following the laboratory activities are classroom activities, which involve both discussions with animations and illustrations, and construction of iconic representations in order to understand and explain the behavior of molecules at submicroscopic level. Afterwards, students infer the relationship between and among gas properties, and derived the mathematical relationships based on the observations at macroscopic level and on the animations used and illustrations constructed at microscopic level. This phase of the lesson utilizes symbols, equations, graphical representations and calculation associated with the quantitative nature of Chemistry. From this derivation, problem solving was employed. After employing IMMSA, questions and clarifications were entertained. The topic then concluded after the verification stage. (Refer to Appendix $B$ for the sample IMMSA flow in teaching diffusion.)

\section{RESULTS AND DISCUSSIONS}

\section{Performance Level of the Students in Chemistry.}

Table 1. Performance Levels of Students in Chemistry

\begin{tabular}{llllll}
\hline Group & $\begin{array}{l}\text { W. } \\
\text { Mean }\end{array}$ & SD & t-value $^{\mathrm{a}}$ & $\mathbf{P}$-value & $\begin{array}{l}\text { Qualitative } \\
\text { Description }\end{array}$ \\
\hline Pre-test & & & & & \\
\hline CLM & 19.27 & 6.92 & $6.01^{* *}$ & $\mathrm{p}<0.01$ & Below Average \\
\hline IMMSA & 18.13 & 5.17 & $8.89^{* *}$ & $\mathrm{p}<0.01$ & Below Average \\
\hline Post-test & & & & & \\
\hline CLM & 22.20 & 5.98 & $5.05^{* *}$ & $\mathrm{p}<0.01$ & Below Average \\
\hline IMMSA & 25.07 & 5.26 & $3.63^{* *}$ & $\mathrm{p}<0.01$ & Below Average \\
\hline
\end{tabular}

a Based on the comparison between w. and hypothetical mean $(H M=30.00)$ **highly significant

Both the pre-test performances of the two groups were much lower than the standard of $75 \%$ set by the secondary school, as this tool was administered to the students before KMT was taken up and discussed. This non-exposure to the stimulus is supported by Gilbert (2008) who argued that experiments, pictures and illustrations are needed in the production and storage of internal representation, which makes oneself capable of mental use.

Like the pre-test performances, both the gro ups also underperformed as the students did not attain or go beyond the standard. Three reasons might contribute to this underperformance: higher grading standard, exposure constraints, and broader content requiring more instructional time. Among these, the post-test performance due to exposure constraints was noted since the Science curriculum of the school has not followed the spiral curriculum prescribed by the education department, thereby lacking progression and continuity. According to Resurrecion and Adanza (2015), progression and continuity in learning Science target the development of thinking and skills, which do not stop at identification.

\section{Mean Improvements in the Student Performance in Chemistry.}

Table 2. Mean Gains in Students' Performance in Chemistry

\begin{tabular}{lrrrrr}
\hline Group & $\begin{array}{r}\text { Pre-test } \\
\text { Mean }\end{array}$ & $\begin{array}{r}\text { Post-test } \\
\text { Mean }\end{array}$ & SD & t-value & P-value \\
\hline CLM & 19.27 & 22.20 & 3.31 & $3.43^{* *}$ & $\mathrm{p}<0.01$ \\
\hline IMMSA & 18.13 & 25.07 & 4.15 & $6.48^{* *}$ & $\mathrm{p}<0.01$ \\
\hline ** highly significant & & & &
\end{tabular}

Both groups had a significant improvement in Chemistry performance of the students, as both CLM and IMMSA were able to let them develop certain key competencies required by the education system. The improvement in the performance of the students taught using CLM was backed by the study of Saville, Cox, O'Brien and Vanderveldt (2011), which found that lectures contributed to higher mean scores than those without lecture conditions.

On the other hand, the significant mean improvement brought about by IMMSA could be due to the fact that physical objects were given to the students during the macroscopic level where they manipulate and use observations leading to better understanding in the microscopic and symbolic levels, illustrating the findings of Bütüner (2016) that revealed the importance of the use of concrete learning materials in increasing students' success, interest and willingness. The significant improvement was in coherence with Jaber and Boujaoude's (2012) study, which concluded that students' conceptual understanding improved due to the exposure to macroscopic, microscopic and symbolic modes of representing Chemistry concepts.

Comparison of the Mean Gains in Chemistry. The mean gain of the students exposed to IMMSA was significantly higher than those taught using CLM. The smaller mean gain obtained from CLM verified the assertion of Kumar (2004) that the method was not quite suitable in achieving the true aim of Chemistry. 
Table 3. Difference in the Mean Gains of Students' Performance in Chemistry

\begin{tabular}{|c|c|c|c|c|c|}
\hline Group & $\begin{array}{l}\text { Mean } \\
\text { Gains }\end{array}$ & SD & Difference & t-value & P-value \\
\hline CLM & 2.93 & 3.31 & \multirow{2}{*}{4.01} & \multirow{2}{*}{$2.926^{* *}$} & \multirow{2}{*}{$\mathrm{p}<0.01$} \\
\hline IMMSA & 6.94 & 4.94 & & & \\
\hline
\end{tabular}

The effective nature of IMMSA in teaching Chemistry concepts was in consonance with Bruner's Three-tiered model of learning which stated that learning should be taught from concrete to abstract levels, leading to a balance in the curriculum. Noted in this sequence of learning activities is the essential use of laboratory experiments which provided insights to the exploration of the five postulates of KMT of gases, thereby leading the students to develop science process skills such as observation and inference skills (Tan, 2015). This could be due to the fact that the macroscopic activities included reflect everyday phenomena that students observe and do. These experiments let them observe diffusibility of substances in solid, liquid and gas, investigate how pressure affects sipping of liquid through a straw, among others. When these basic, everyday concepts are understood, the students could use these as essential knowledge and skills for understanding more complex chemical systems and phenomena, such as those properties occurring in pressure cookers, popcorn popping and can implosion. Students anchor complex phenomena to basic course understanding in Chemistry rooted to contextualized scenarios (Giamellaro, 2014).

The experiments create stimuli that gave cues to the students about the phenomena in the submicroscopic world (Balushi, 2013). The iconic representations that students made were constructed using dots as rigid particles and arrows as direction of particle motion. The results of the experiments helped the students understand the construction of the models, which gave meaning to them concerning the submicroscopic world (Ainsworth, 2007). These models clearly show how particles behave, and how these particles are affected when conditions are changed, such as lowering the pressure, increasing the temperature and maintaining a particular volume. This led to an effective construction of mental models among the students in the symbolic level (Sunyono and Ibrahim, 2015).

The constructed written models created an effective means of understanding Chemistry when calculations are involved. The clarity of the written representation of the behavior of particles paved way to succinct understanding of the relationship among the properties of gases and the postulates of KMT. Understanding the basic relationships of the relationship between such properties becomes a vehicle of effectively accomplishing problem-solving tasks in Chemistry (Marais and Jordaan, 2010).

In this sequence of learning activities, students, together with their teachers who act as facilitators rather than dispenser of knowledge, explored ideas, solved problems, and reflected on meaning (Ellis, 2001). Moreover, this finding adhered with Johnstone's Chemistry triangle which stated that learning the subject should come in a variety of learning experiences through the use of macroscopic, microscopic and symbolic modes of representation. This indicates that in making learning plans in Chemistry, several modes of representations should be incorporated, giving opportunities to students to look at the subject matter in multidimensional way.

To sum up, the interplay of the varying learning experiences brought about by IMMSA in dealing with concepts of KMT of gases resulted in a positive, significant outcome in the improvement of students' understanding. With this, several problems arising in the understanding of the Chemistry Triangle might have been addressed, including the lack of macroscopic experience, misconceptions of subatomic nature of matter, deficiency in utilizing complex conventions in symbolic level, and the inability to move in between levels. Such interplay of experiences made the students manifested a sense of learning and understanding of Chemistry concepts and chemical systems, such as gases and gas laws (Gilbert and Treagust, 2009).

\section{CONCLUSION AND RECOMMENDATIONS}

Teaching scientific concepts should be systematically and inductively done. In particular, Chemistry instruction should be taught in sequential order from concrete to abstract, and use different modes of representation at appropriate time and levels. In this way, perspective on the difficulty of Chemistry changes as learning the subject becomes more meaningful and relevant to the students. The Integrated MacroMicro-Symbolic Approach in teaching Chemistry was effective as seen in the students enhanced performance; thus, affirming the value of Three-tiered model of learning and Chemistry triangle in the 21st century learning environments.

The study recommends that, as basis for future researches, be used to come up with possible improvements in determining the effectiveness of IMMSA in a bigger sample, in teaching other areas in Chemistry, such as Organic and Biological Chemistry, and using multiple case studies with different teachers. 


\section{REFERENCES}

Al-Balushi SM. The effect of different textual narrations on students' explanations at the submicroscopic level in Chemistry. EURASIA J Math, Sci Tech Ed. 2013; 9(1):3-10. Available from https://doi.org/10.12973/eurasia.2013.911a doi: 10.12973/eurasia.2013.911a

Ainsworth S. The educational value of multiple representations when learning complex scientific concepts. Visualization: Theory and practice in Science education. Springer Science and Business Media; 2007. p. 191-208

Bradley J. Chemistry education for development [Internet]. 2005 [cited 2017 Jan 4]. Available from http://old.iupac.org/publications/cei/vol6/03_ Bradley.pdf

Bradley J. The Chemist's triangle and a generic systemic approach to teaching, learning and research in Chemistry education. Afr J Chem Ed. 2014; 4:64-79

Brandiet A. Investigating students' understanding of the symbolic, macroscopic, and particulate domains of oxidation-reduction and the development of the redox concept inventory [dissertation]. [Ohio]: Miami University. 2014, 422 p.

Bruner J. Toward a theory of instruction. Cambridge: Belkapp Press; 1966

Bütüner SÖ. The use of concrete learning objects taken from the history of mathematics in mathematics education. Int J Math Educ Sci Tech. 2016. Available from http://www.tandfonline.com/ doi/abs/10.1080/0020739X.2016.1184336 doi: 10.1080/0020739X.2016.1184336

Cardellini L. Chemistry: Why the subject is difficult?. Educacion Quimica. 2012; 1-6

Childs PE, Sheehan M. What's difficult about Chemistry? An Irish perspective. Chem Educ Res Pract. 2009; 10:204-218. Available from http:// pubs.rsc.org/en/content/articlehtml/2009/rp/ b914499b doi: 10.1039/b914499b

Department of Education. $\mathrm{K}$ to 12 curriculum guide: SCIENCE (grades 3 to 10) [Internet] . 2013 [cited 2017 Jan 4]. Available from http:// www.deped.gov.ph/sites/default/files/page/2014/ Final\%20Science\%20CG\%20310\%2005.08.2014. pdf
Eilks I, Hofstein A. Relevant Chemistry education: From theory to practice. Rotterdam: Sense Publishers; 2015

Ellis A. Teaching, learning, and assessment together: The reflective classroom. New York : Eye on Education, Inc.; 2001

Giamellaro M. Primary contextualization of Science learning through immersion in contentrich settings. Int J Sci Educ. 2014; 36(17):28482871. Available from http://www.tandfonline.com/ doi/abs/10.1080/09500693.2014.937787 doi: $10.1080 / 09500693.2014 .937787$

Gilbert J. Visualization: An emergent field of practice and enquiry in Science education. Visualization: Theory and practice in science education. Springer Science and Business Media; 2008

Harrison, A. and Treagust, D. The particulate nature of matter: Challenges in understanding the submicroscopic world. Chemical education: Towards research-based practice. Dordrecht: Kluwer Academic Publishers; 2002. p. 189-212

Gilbert J, Treagust D. Multiple representations in chemical education. Springer Science + Business Media B.V.; 2009

Jaber L, Boujaoude S. A macro-micro-symbolic teaching to promote relational understanding of chemical reactions. Int J Sci Educ. 2012; 34:973998. Available from http://www.tandfonline.com/ doi/abs/10.1080/09500693.2011.569959 doi: $10.1080 / 09500693.2011 .569959$

Johnstone A. Macro- and micro-chemistry. School Science Review. 1982; 64:377-379

Kincheloe J, Horn R. The Praeger handbook of education and psychology, Vol. 1. Connecticut: Praeger Publishers; 2007

Kumar K. Methods of teaching Chemistry. New Delhi: Discovery Publishing House; 2004

Li WSS, Arshad MY. Applications of multiple representation levels in redox reactions among tenth grade Chemistry teachers. J Turk Sci Educ. 2014; 11:35-52. Available from http://www.tused.org/ internet/tused/ARCHIVE/v11/i3/tusedv11i3s3.pdf doi: $10.12973 /$ tused.10117a

Marais P, Jordaan F. Are we taking symbolic language for granted? J Chem Educ. 2000; 77(10):1355-1357. Available from http://pubs.acs.org/doi/abs/10.1021/ ed077p1355 doi:10.1021/ed077p1355 
Nelson PG. Teaching Chemistry progressively: From substances, to atoms and molecules, to electrons and nuclei. Chem Educ Res Pract Eur. 2002; 3:215228. Available from http://pubs.rsc.org/en/content/ articlelanding/2002/rp/b2rp90017c\#!divAbstract doi:10.1039/B2RP90017C

Resurrecion JE, Adanza J. Spiral progression approach in teaching Science in selected private and public schools in Cavite. Proceedings of the DLSU Research Congress. 2015; 3:1-12. Available from http://www.dlsu.edu.ph/conferences/dlsu_ research_congress/2015/proceedings/LLI/017LLI_ Resurrecion_GF.pdf

Risch B. Teaching Chemistry around the World. Munster : Verlad; 2010

Royal Society of Chemistry Global frameworks for Chemistry education for 11-14 and 14-16 age ranges [Internet]. 2011 [cited 2017 Jan 4] Available from http://www.rsc.org/images/DEVELOPING\%20 A \% 20 G LOBA L \% 20 F RAM E W O R K \% 20 FOR\%20CHEMISTRY\%20EDUCATION_ tcm8207914.pdf

Saville BK, Cox T, O’Brien S, Vanderveldt A. Interteaching: The impact of lectures on student performance. J Appl Behav Anal. 2011; 44:937941. Avaibable from doi:10.1901/jaba.2011.44-937

Schoen A. Reflections on problem solving theory and practice. Math J. 2013; 10:1-2

Sirhan G. Learning difficulties in Chemistry: An overview. J Turk Sci Educ. 2007; 4-2-20

Sunyono, Yuanita L, Ibrahim M. Mental models of students on stoichiometry concept in learning by method based on multiple representations. Online J New Horiz Educ. 2015; 5(2)

Tan R. Improving the use of physical manipulatives in teaching science concepts through lesson study. Int J Lesson Learn Stud. 2015; 4 (4)-328-342. Available from http://www.emeraldinsight.com/doi/ abs/10.1108/IJLLS-01-2015-0001 doi:10.1108/ IJLLS-01-2015-0001

Woldeammanuel M, Atagana $\mathrm{H}$, Engida T. What makes Chemistry difficult?. Afr J Chem Educ. 2014; 4(2):31-43

Wood L. Representing Chemistry: How instructional use of symbolic, microscopic and macroscopic modes influences student conceptual understanding in Chemistry [dissertation]. Arizona: Arizona State University. 2013, 161 pp. 


\section{APPENDIX}

A. Sample Section of the Researcher-Constructed Assessment Tool Situation: Lorenzo cooks pork stew using a pressure cooker.

1. What will happen to the time utilized in cooking pork stew?
A. Cooking time will depend on the type of the cooker.
B. Cooking time will be longer than that in a normal stove.
C. Cooking time will be shorter than that in a normal stove.
D. Cooking time will stay the same as cooking in a normal stove.

2. Why do you think your answer is no.1 will happen? (constructive response)

3. The cooker has a metal container which is sealed airtight. Which of the following is CORRECT?

A. The steam molecules escape, thereby decreasing the number of collisions among molecules.

B. The steam molecules accumulate, thereby increasing the number of collisions among molecules.

C. The steam molecules become excited, thereby decreasing the number of collisions among molecules.

D. The steam molecules lower its kinetic energy, thereby increasing the number of collisions among the molecules.

4. How do you represent the behavior of the molecules in no. 3? Illustrate it below. (constructing response)

5. What is the relationship of the number of collisions among molecules and the pressure inside the cooker?
A. no relationship at all
B. directly proportional
C. inversely proportional
D. exponentially proportional

6. At a pressure of $3.0 \mathrm{~atm}$, the number of collisions among steam molecules in a particular pressure cooker is approximately $2.0 \times 10^{3}$ collisions. If the cooker is opened, the pressure is reduced to 1.5 atm. How many collisions are there then? (problem-solving response)

B. Sample IMMSA flow in teaching Diffusion

Learning Activity 1: Laboratory Experiment (2 days=1 hour and 40 minutes)

1. Prelab: Students are asked about diffusibility and diffusion.

2. Lab Proper: Students are engaged in four experiments on the diffusibility of gases, liquids and solids, and on the relative rates of gas diffusion. While doing the experimental procedures, they are to observe and record their results in a tabular format. Cleaning the working area, and returning of apparatus follow.

3. Postlab: Students are to answer analysis questions, and write conclusion derived from the results of the experiment.

Learning Activity 2: Illustration Activity ( 2 days $=1$ hour and 40 minutes)

1. Pre-construction: Students are asked questions related to the lab experiment done.

2. Construction Proper: Students are divided into four groups. Each group is tasked to construct an illustration out of the results of the experiment done. For example, the students will illustrate the behavior of the molecules during diffusibility in a gas.

3. Post-construction: One representative from each group explains the illustration in terms of the behavior of molecules during diffusion process.

Learning Activity 3: Problem Solving ( 2 days=1 hour and 40 minutes)

1. Pre-problem solving: Students are asked about the relationship between molecular mass and diffusion rate, molar mass and distance traveled, and molar mass and diffusion time. This primary questioning leads to the derivation of Graham's Law, the principle governing diffusion of gases: $r_{1} \sqrt{M_{1}}=r_{2} \sqrt{M_{2}}$.

2. Problem Solving: After inferring the relationships above and derivation of Graham's Law, the students are to answer one or two conceptual problems. Then, problem solving activities are employed to them, where their answers follow the GAFSA format (Given, Asked, Formula, Solution and Answer).

3. Post-problem solving: Checking of papers follows. After this, one or two students are asked to create situations where Graham's Law could be applied. This serves as the conclusion and verification stage of the lesson. 